\title{
Computational Screening of new High Voltage Insulation Gases with Low Global Warming Potential
}

\section{Journal Article}

Author(s):

Rabie, Mohamed; Franck, Christian (1)

Publication date:

2015-02-12

Permanent link:

https://doi.org/10.3929/ethz-b-000097899

Rights / license:

In Copyright - Non-Commercial Use Permitted

Originally published in:

IEEE Transactions on Dielectrics and Electrical Insulation 22(1), https://doi.org/10.1109/TDEI.2014.004474 


\title{
Computational Screening of new High Voltage Insulation Gases with Low Global Warming Potential
}

\author{
Mohamed Rabie and Christian M. Franck \\ Power Systems and High Voltage Laboratories, ETH Zurich, 8092 Zurich, Switzerland
}

\begin{abstract}
We systematically screen chemical compounds for their suitability as high voltage insulation gases on the basis of electrical, environmental and safety characteristics. Recently, 1234 compounds were identified out of a library of over 56000 chemicals by means of virtual screening. The authors applied filters for the global warming potential (GWP), toxicity, stability, flammability and critical temperature to find promising candidate refrigerant fluids. We estimate the electric strength (ES) and the boiling point of these environmentally friendly compounds to select promising SF 6 replacement candidates. The most promising candidates within our method are predominantly Fluoro-alkenes, -alkylsulfides, -alcohols and-alkylamines. In addition, risk and safety data was compiled for compounds that are supplied by chemical vendors at this date, resulting in 7 preliminary candidates.
\end{abstract}

Index Terms — Dielectric breakdown, gas insulation, SF6.

\section{INTRODUCTION}

SULFUR hexafluoride ( $\mathrm{SF}_{6}$ ) has a high electric strength value (ES) and therefore is widely used in electrical equipment. In addition to its very good insulation properties $\mathrm{SF}_{6}$ is non-toxic, inert and has a low boiling point $\left(T_{\mathrm{B}}\right)$. Due to its long atmospheric lifetime and large radiative forcing it is a greenhouse gas with high global warming potential (GWP). A reduction of the atmospheric concentration of this long-lived gas can only be achieved by stopping emissions. Therefore, considerable effort has been undertaken for finding substitute insulation gases or gas mixtures with significantly lower GWP [1-4].

Characteristics sought in $\mathrm{SF}_{6}$ replacement gases are mainly chemical stability, low toxicity, low flammability, low GWP, high ES and boiling point ranges that are suitable for high voltage applications. Considering the enormous number of all conceivable molecules it is time consuming to determine their properties by performing individual experiments. Thus, a systematic search using computer programs is desirable to find promising candidates. Such filtering techniques, known as virtual screening [5], are an integral part of e.g. drug discovery research and material design. They are used to identify structures with the desired properties from a very large library of compounds. It is efficient to apply first filters for properties that can be determined directly, without high computational costs, such as the mass or the elemental composition of a molecule. Subsequently, filters that are estimated by computationally expensive methods such as molecular geometry optimizations can be applied.
A set of 1234 candidate refrigerant fluids was identified by means of virtual screening from the PubChem database of the National Institute of Health [6,7]. The environmental and safety criteria applied by the authors to this large number of molecules were: low GWP, low LFL (lower flammability limit), and filters for toxicity and chemical stability.

In this work, we subsequently investigate the remaining 1234 molecules by a computational method that estimates the ES and $T_{\mathrm{B}}$ of electronegative gases, to identify potential $\mathrm{SF}_{6}$ substitutes $[8,9]$. The present paper is structured as follows: Section 2 reviews the methods and constraints of the environmental and safety filters from [6]. Then we briefly describe our method that estimates the ES and $T_{\mathrm{B}}$ of electronegative gases by means of density functional theory (DFT) calculations. Further, the filtering procedure to select the most promising compounds is given. In Section 3 we present the results of our analysis. We compare the estimated values of $T_{\mathrm{B}}$ for the most promising candidates with values given in literature. In addition, risk factors and safety features for the gas handling are collected for commercially available compounds. In section 4 our filtering results as well as the underlying filtering procedure are discussed. Finally, in section 5 we conclude with the benefit of our study based on the applied screening criteria.

\section{METHODS}

\subsection{ENVIRONMENTAL CHARACTERISTICS}

We attempt to calculate the ES of only environmentally friendly and safe molecules. To avoid unnecessary computation of molecules that may reveal good insulation 
properties but are harmful to health or environment, the starting point of our gas screening is, instead of the entire library of the PubChem database, only the set of molecules that are the filtering results from [6]: The authors limit the molecular size to maximum 15 atoms and allow only compositions of the elements: $\mathrm{C}, \mathrm{H}, \mathrm{F}, \mathrm{Cl}, \mathrm{Br}, \mathrm{N}$ and $\mathrm{S}$. Further, filters for toxicity and stability were based on functional groups. The critical temperature $T_{\mathrm{c}}$ of chemicals used as refrigerant fluids should be in the range of $300 \mathrm{~K}<T_{\mathrm{c}}$ $<550 \mathrm{~K}$, due to technical aspects described in [6]. The lower flammability was limited to LFL $>0.1 \mathrm{kgm}^{-3}$. The chosen LFL is the boundary value of "Class 2" flammability in the ASHRAE refrigerant classification standard [10], which corresponds to a "moderate" [6] flammable compound.

For the estimation of the GWP the authors calculated two properties of a compound, the atmospheric lifetime $(\tau)$ and the radiative efficiency (RE) [6]. The GWP is defined as the radiative forcing $(\mathrm{RF})$ due to an instantaneous release of $1 \mathrm{~kg}$ of a trace substance integrated over a chosen time horizon, relative to that of $1 \mathrm{~kg}$ of $\mathrm{CO} 2$. For the RF, the IPCC uses the following definition: "The RF of the surface-troposphere system due to the perturbation in or the introduction of an agent (say, a change in greenhouse gas concentrations) is the change in net (down minus up) irradiance (solar plus longwave, in $\mathrm{Wm}^{-2}$ ) at the tropopause after allowing for stratospheric temperatures to readjust to radiative equilibrium, but with surface and tropospheric temperatures and state held fixed at the unperturbed values" [11]. The RE is the change of the RF per unit increase in atmospheric concentration. The authors selected the PM6 [12] semiempirical method for computing vibrational frequencies and IR intensities, providing in comparison to other semiempirical methods more consistent results for RE. Even though the computationally more expensive DFT methods are in better agreement with experimental RE data, the accuracy of the PM6 method is still reasonable for screening purposes. To obtain RE, the authors calibrated the semiempirical calculations by a uniform vibrational frequency factor, based on a comparison between the predicted data and a given experimental data set. The GWP was evaluated over a time horizon of 100 years assuming an exponential decay for the time evolution of the gas in the atmosphere with a rate of $1 / \tau$. Here, the decay mechanism accounts for compound removal via reactions with $\mathrm{OH}$ only. The rate coefficient for this reaction was calculated by means of group-contribution method [13]. Subsequently, the lifetimes were estimated as the inverse reaction rate coefficient times an empirical parameter which was determined by comparison with reported lifetime data. Chemical reactions with atmospheric compounds other than $\mathrm{OH}$ as well as loss mechanisms such as ultraviolet photolysis, rainout or wet deposition were not considered by the authors. The calculations for the lifetimes and RE were performed with the Gaussian 09 package [14].

The constraint for the GWP was set to GWP $<200$. This value is based on the current policy outlook [15]. For the remaining set of molecules the GWP is mainly controlled by atmospheric lifetimes, which are in the range from 0.02 years to 6 years.

\subsection{ESTIMATION OF ES AND $\mathrm{T}_{\mathrm{B}}$}

Those compounds that pass the environmental filtering criteria from Section 2.1 are given in [6]. We subsequently investigated these compounds in more detail estimating two crucial properties for their potential usage in high voltage equipment: the electric strength ES and the boiling point $T_{\mathrm{B}}$. The calculation of the ES by means of simulation of electron dynamics on the basis of microscopic electron-molecule collisions is a challenging problem. The required input for the underlying fluid modelling is at least a complete set of cross sections for all relevant elastic and inelastic two-body processes [16]. In addition, Boltzmann solvers as well as Monte Carlo methods in general do not account for three-body processes, which may get relevant at higher pressures $[17,18]$. Facing these difficulties of kinetic modelling, several empirical estimation methods for the ES have been developed, analyzing the correlation between the ES, as well as $T_{\mathrm{B}}$, and certain molecular properties [19-23]. Stronger correlations than in these studies, we could find in a previous work by means of predictor variables [8], which are simple functions of the molecular properties: electric dipole moment, average static electronic polarizability, vertical/adiabatic ionization energy, vertical/adiabatic electron affinity, electron number and molecular mass. These properties were calculated abinitio for isolated gas molecules whose structure has been optimized in the electronic ground state. Vibrational and temperature corrections have been neglected. The Kohn-Sham DFT calculations were performed with the Turbomole program package [24] employing the BP86 density functional $[25,26]$ together with density fitting techniques. We applied Ahlrichs' polarized valence triple-zeta basis def-TZVP [27] in the calculations of the vertical/adiabatic ionization energy and the vertical/adiabatic electron affinity. The larger def2QZVPP basis set [28] was used for the calculation of the electronic polarizability and dipole moment. We evaluate energy differences between potential curves of neutral and cation and of neutral and anion, neglecting the discrete structure of the vibrational energy levels. The dipole moment and polarizability are then calculated for the geometryoptimized neutral molecule. In the following, we write $E_{\mathrm{r}}$ for the ES relative to $\mathrm{SF}_{6}$. Our method has a standard deviation of $\sigma=0.35$ for $E_{\mathrm{r}}$ and $\sigma=28 \mathrm{~K}$ for $T_{\mathrm{B}}$.

\subsection{FILTERING BASED ON ES AND $\mathrm{T}_{\mathrm{B}}$}

In a next step towards gases that are suitable for high voltage insulation we apply constraints for the ES and $T_{\mathrm{B}}$. The remaining compounds are subsequently investigated by means of Pareto efficiency in the design space with $E_{\mathrm{r}}$ and $T_{\mathrm{B}}$ as parameters. Finally, to arrange the remaining substances according to their environmental impact, we subdivide our results into four groups of GWP. The reduction of the initial number of compounds by the individual steps is illustrated in Table 1.

The ideal insulation gas would suppress electron avalanches up to high electric fields, corresponding to high values of the 
Table 1. Filtering steps for the 1234 molecules with GWP $<200$.

\begin{tabular}{c|c|c}
\hline Filter & constraint & $\begin{array}{c}\text { \# of remaining } \\
\text { compounds }\end{array}$ \\
\hline$T_{\mathrm{B}}$ & $T_{\mathrm{B}}<320 \mathrm{~K}$ & 408 \\
\hline$E_{\mathrm{r}}$ & $\mathrm{ER}>0.5$ & 384 \\
\hline $\begin{array}{c}\text { Pareto front with } \\
\sigma \text {-area }\end{array}$ & $\begin{array}{c}\sigma=0.35 \text { for } E_{\mathrm{r}} \sigma \\
=28 \mathrm{~K} \text { for } T_{\mathrm{B}}\end{array}$ \\
\hline
\end{tabular}

ES. At the same time the breakdown voltage for typical dimensioning of high voltage equipment increases with increasing gas pressure, according to the linear regime of Paschen's law [29]. Thus, a high vapor pressure at typical ambient temperatures, corresponding to a low $T_{\mathrm{B}}$, is desirable to achieve high breakdown voltages without condensation of the gas. We do not want to exclude compounds which could be used in gas mixtures of two or more components. Therefore, we choose more generous constraints ES $>0.5$ and $T_{\mathrm{B}}<320 \mathrm{~K}$ as one would choose for a pure insulation gas.

Furthermore, we identify the Pareto efficient compounds of the remaining set with the most promising candidates. Here, a Pareto efficient molecule means the "best" option for the ES and simultaneously $T_{\mathrm{B}}$ : it is not possible to find a single molecule with higher $E_{\mathrm{r}}$ value and at the same time lower $T_{\mathrm{B}}$. We determine the set of all Pareto efficient compounds, which is defined as the Pareto frontier. Again, to not exclude interesting candidates we incorporate all molecules in the $\sigma$ region around the Pareto frontier. This region we will call in the following Pareto-area.

In the context of high voltage insulation a molecule's GWP is commonly compared to one of the two prominent greenhouse gases: $\mathrm{SF}_{6}$ or $\mathrm{CO}_{2}$. On the one hand, all compounds would represent a drastic improvement to $\mathrm{SF}_{6}$ in terms of environmental impact. On the other hand, in comparison to $\mathrm{CO}_{2}$, there is still a high variation between 0 and 200. Hence, to have an overview of the different environmental impacts of the remaining compounds we subdivide them into four different groups according to their GWP: GWP $<1,1<$ GWP $<10,10<$ GWP $<100$ and $100<$ GWP $<200$.

\section{Results}

According to Section 2.2 we estimate $E_{\mathrm{r}}$ and $T_{\mathrm{B}}$ of a set of 1234 compounds that are the filtering results from [6], as described in Section 2.1. The results are presented in Figure 1a. The constraints for $E_{\mathrm{r}}$ and $T_{\mathrm{B}}$ result in 384 compounds. In Figure $1 \mathrm{~b}$ we identify the Pareto frontier of the remaining data, created by a set of 15 molecules. Including all molecules in the $\sigma$-region we count 141 Pareto-compounds, which we identify as superior candidates.

These Pareto- compounds were split into four groups with respect to the GWP as described above. The results for the estimated $T_{\mathrm{B}}$ and $E_{\mathrm{r}}$ are illustrated in Figure 2. In addition, when available, values for $T_{\mathrm{B}}$ from literature were given. For better comparison between the different groups the Pareto frontier from Figure $1 \mathrm{~b}$ is indicated in each panel. The number of compounds $\mathrm{N}$ in each GWP- windows is given in the inset of the corresponding panel.

$G W P<1$ : The set of compounds with GWP $<1$ are
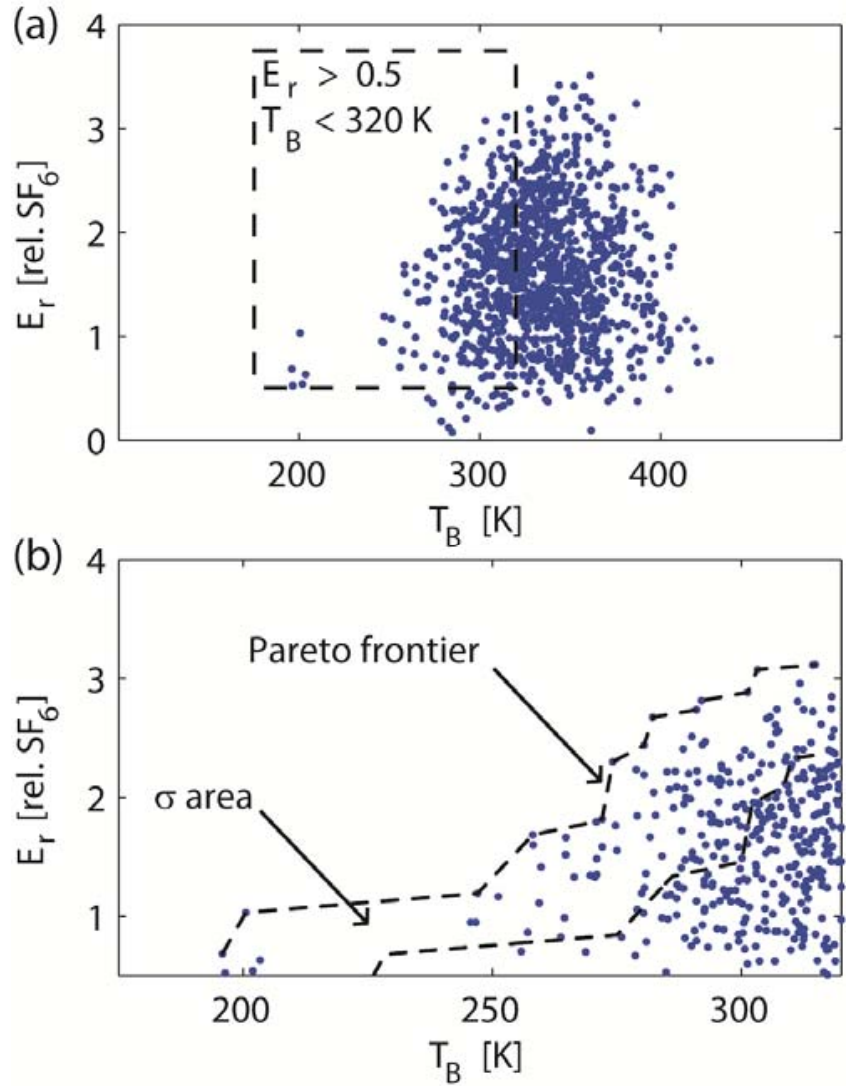

Figure 1. (a) estimated electric strength $E_{\mathrm{r}}$ relative to $\mathrm{SF}_{6}$ vs estimated boiling point $T_{\mathrm{B}}$ for 1234 molecules (dots). (b) inset of upper panel: 384 remaining compounds (dots) after filtering with $T_{\mathrm{B}}<320 \mathrm{~K}$ and $E_{\mathrm{r}}>0.5$. The Pareto frontier (upper dashed line) and its standard deviation (lower dashed line) confine the ideal candidate gases.

supposed to be the less detrimental to environment among the Pareto-compounds and are given in Table 2. The list contains only Fluoro-alkenes containing one or two hydrogen atoms. However, there is one exception: the Fluoroethanethiol $\mathrm{C}_{2} \mathrm{HF}_{5} \mathrm{~S}$. For the latter we estimated an ES clearly higher than $\mathrm{SF}_{6}$. At the same time it has a high reaction rate with $\mathrm{OH}$ resulting in an estimated lifetime below one day [6]. The ES of each of the four isomers of $\mathrm{C}_{4} \mathrm{H}_{2} \mathrm{~F}_{6}$ is around two times larger than for $\mathrm{SF}_{6}$. The atmospheric lifetimes of the same compounds are of around two days [6]. The compound 91450 has a vapor pressure of 1.2 bar at $20{ }^{\circ} \mathrm{C}$ [30], whereas 52991879 has a vapor pressure of 0.6 bar at $20{ }^{\circ} \mathrm{C}$ [30]. We find agreement between our calculated $T_{\mathrm{B}}$ values and values from literature within the $1 \sigma$ - uncertainty. Furthermore, Table 2 contains seven Fluoro-alkenes of the form $\mathrm{C}_{5} \mathrm{HF}_{9}$ and two isomers of $\mathrm{C}_{5} \mathrm{H}_{2} \mathrm{~F}_{8}$. The list contains a single Perfluoro-alkene which is the cyclic alkene $\mathrm{C}_{5} \mathrm{~F}_{8}$.

$1<G W P<10$ : Here, the Fluoro-alkenes represent again the dominant group. Further Table 3 contains the Fluoroalkylsulfides C2F6S, C3F8S and C4F10S, as well as the Fluoroalcohols $\mathrm{C} 4 \mathrm{H} 3 \mathrm{~F} 7 \mathrm{O}$ and $\mathrm{C} 4 \mathrm{H} 4 \mathrm{~F} 6 \mathrm{O}$. The $T_{\mathrm{B}}$ values for the compounds found in literature agree all with the calculated values within the accuracy.

$10<G W P<100$ : Table 4 shows the compounds of the Pareto frontier. Here, in addition to certain Fluoro-alkenes and Fluoro-alcohols, the group of Fluoroalkyl-amines such as 
$\mathrm{C} 3 \mathrm{H} 2 \mathrm{~F} 7 \mathrm{~N}$ or $\mathrm{C} 3 \mathrm{H} 3 \mathrm{~F} 6 \mathrm{~N}$, represent possible candidates. For the compounds 2776724, 13529, 9872 and 12223 the estimated values of $T_{\mathrm{B}}$ are clearly outside the $1 \sigma$ - uncertainty.

$100<G W P<200$ : The Pareto compounds with the highest GWP values are given in Table 5. Basically, the same chemical classes as before represent the most important candidates.

For all compounds from Tables 2-5 which are, to our level of
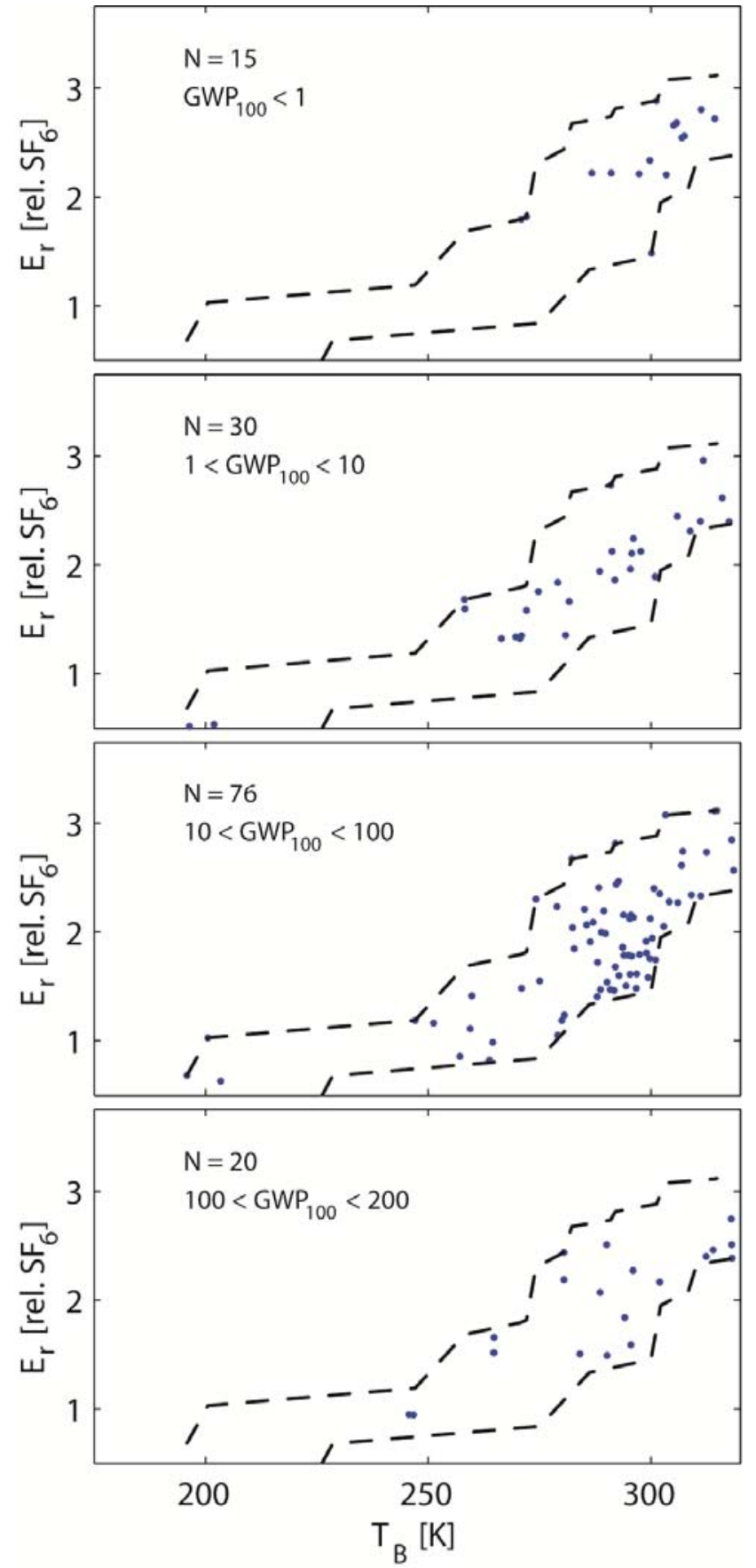

Figure 2. Estimated electric strength $E_{\mathrm{r}}$ relative to $\mathrm{SF}_{6}$ vs estimated boiling point $T_{\mathrm{B}}$ for the 141 Pareto efficient molecules (dots). From top to bottom panel: compounds with GWP $<1,1<\mathrm{GWP}<10,10<\mathrm{GWP}<100$ and 100 $<$ GWP $<200$. The number of compounds $\mathrm{N}$ in each GWP interval is given in the inset of each panel. The dashed lines correspond to the Pareto frontier and its standard deviation of Figure 1(b), as described in the text. knowledge, commercially available at this date we collected information from safety data sheets provided by the vendors. Table 6 lists for these compounds the safety and risk phrases defined in Annex III and Annex IV of European Union Directive 67/548/EEC. For comparison the safety and risk phrases for $\mathrm{SF}_{6}$ are given. According to our filtering procedure the final list of candidate gases should only contain non-toxic and non-flammable compounds. However, Table 6 contains certain gases that are in terms of risk phrases (R23) "toxic by

Table 2. Compounds in the Pareto-area with GWP $<1$.

\begin{tabular}{c|c|c|c|c}
\hline CID & formula & $T_{\mathrm{B}}$ & $T_{\mathrm{B}}$ (lit.) & $E_{\mathrm{r}}$ \\
\hline 4713114 & C2HF5S & 300 & & 1.5 \\
\hline 5708528 & C4H2F6 & 271 & $282[30]$ & 1.8 \\
\hline 2774975 & C4H2F6 & 272 & & 1.8 \\
\hline 91450 & C4H2F6 & 297 & $288[30]$ & 2.2 \\
\hline 52991879 & C4H2F6 & 303 & $306[30]$ & 2.2 \\
\hline 11212 & C5F8 & 300 & $300[30]$ & 2.3 \\
\hline 18520951 & C5H2F8 & 291 & & 2.2 \\
\hline 53395640 & C5H2F8 & 287 & & 2.2 \\
\hline 53395686 & C5HF9 & 305 & $303-306[30]$ & 2.7 \\
\hline 12530412 & C5HF9 & 306 & & 2.7 \\
\hline 12951075 & C5HF9 & 307 & & 2.5 \\
\hline 53395684 & C5HF9 & 307 & & 2.6 \\
\hline 11053485 & C5HF9 & 301 & $306-307[30]$ & 2.9 \\
\hline 23234730 & C5HF9 & 311 & & 2.8 \\
\hline 12951076 & C5HF9 & 314 & & 2.7 \\
\hline
\end{tabular}

Table 3. Compounds in the Pareto-area with $1<\mathrm{GWP}<10$.

\begin{tabular}{|c|c|c|c|c|}
\hline CID & formula & $T_{\mathrm{B}}$ & $T_{\mathrm{B}}$ (lit.) & $E_{\mathrm{r}}$ \\
\hline 8301 & $\mathrm{C} 2 \mathrm{~F} 4$ & 202 & $197[31]$ & 0.5 \\
\hline 136206 & C2F6S & 281 & & 1.4 \\
\hline 5365501 & $\mathrm{C} 2 \mathrm{H} 2 \mathrm{~F} 2$ & 196 & 231 [30] & 0.5 \\
\hline 14841 & $\mathrm{C} 2 \mathrm{H} 2 \mathrm{~F} 2$ & 196 & & 0.5 \\
\hline 19779344 & C3F8S & 295 & & 2.0 \\
\hline 19920814 & C4F10S & 306 & & 2.4 \\
\hline 21732342 & C4F10S & 316 & & 2.6 \\
\hline 11389728 & C4F6O & 292 & & 1.9 \\
\hline 61109 & C4F8 & 296 & 280 [7] & 2.2 \\
\hline 2775851 & C4F8 & 258 & 274 [30] & 1.7 \\
\hline 3034116 & C4F8 & 282 & & 1.7 \\
\hline 9678 & C4F8 & 258 & & 1.6 \\
\hline 12705729 & C4F8S & 311 & & 2.4 \\
\hline 21838907 & $\mathrm{C} 4 \mathrm{H} 2 \mathrm{~F} 6$ & 271 & & 1.4 \\
\hline 53395682 & $\mathrm{C} 4 \mathrm{H} 2 \mathrm{~F} 6$ & 270 & & 1.3 \\
\hline 21096849 & $\mathrm{C} 4 \mathrm{H} 2 \mathrm{~F} 6$ & 272 & & 1.6 \\
\hline 13238222 & C4H3F7O & 309 & & 2.3 \\
\hline 21096871 & $\mathrm{C} 4 \mathrm{H} 4 \mathrm{~F} 4$ & 266 & & 1.3 \\
\hline 4712696 & $\mathrm{C} 4 \mathrm{H} 4 \mathrm{~F} 6 \mathrm{O}$ & 301 & & 1.9 \\
\hline 20496975 & C4HF7 & 271 & & 1.3 \\
\hline 5708514 & C4HF7 & 288 & 281 [30] & 1.9 \\
\hline 6110611 & C4HF7 & 296 & & 2.1 \\
\hline 498797 & C4HF7 & 289 & & 1.9 \\
\hline 12633092 & C4HF7 & 298 & & 2.1 \\
\hline 12576087 & C5F10 & 312 & & 3.0 \\
\hline 12576086 & C5F10 & 291 & & 2.7 \\
\hline 155748 & C5F10 & 275 & & 1.8 \\
\hline 2736749 & C5F10 & 279 & & 1.8 \\
\hline 12534876 & C5F10 & 291 & & 2.1 \\
\hline 11471944 & C5HF9 & 318 & & 2.4 \\
\hline
\end{tabular}


inhalation", namely 11212 and 16924. The compound 61109 is "very toxic by inhalation" (R26). The gases 52991879 and 2776724 are "flammable" (R10). The compounds 15914919 and 5365501 are "extremely flammable" (R12), whereas 10154032 "in use, may form flammable/explosive vapor-air

Table 4. Compounds in the Pareto-area with $10<$ GWP $<100$.

\begin{tabular}{|c|c|c|c|c|}
\hline CID & formula & $T_{\mathrm{B}}$ & $T_{\mathrm{B}}$ (lit.) & $E_{\mathrm{r}}$ \\
\hline 19350069 & $\mathrm{C} 2 \mathrm{H} 2 \mathrm{~F} 4 \mathrm{O}$ & 257 & & 0.9 \\
\hline 14529362 & $\mathrm{C} 2 \mathrm{H} 2 \mathrm{~F} 4 \mathrm{O}$ & 264 & & 1.0 \\
\hline 185647 & $\mathrm{C} 2 \mathrm{H} 3 \mathrm{~F} 3 \mathrm{O}$ & 264 & & 0.8 \\
\hline 12223 & $\mathrm{C} 2 \mathrm{H} 4 \mathrm{~F} 2$ & 196 & 304 [30] & 0.7 \\
\hline 21222306 & $\mathrm{C} 2 \mathrm{HBrF} 4 \mathrm{O}$ & 300 & & 2.1 \\
\hline 20342513 & $\mathrm{C} 2 \mathrm{HClF} 4 \mathrm{O}$ & 283 & & 1.8 \\
\hline 2759276 & C2HF5O & 260 & & 1.4 \\
\hline 26343944 & $\mathrm{C} 3 \mathrm{H} 2 \mathrm{~F} 6 \mathrm{O}$ & 294 & & 1.9 \\
\hline 13529 & $\mathrm{C} 3 \mathrm{H} 2 \mathrm{~F} 6 \mathrm{O}$ & 289 & 331 [30] & 2.0 \\
\hline 26343943 & $\mathrm{C} 3 \mathrm{H} 2 \mathrm{~F} 6 \mathrm{O}$ & 294 & & 1.9 \\
\hline 13350568 & $\mathrm{C} 3 \mathrm{H} 2 \mathrm{~F} 6 \mathrm{O}$ & 294 & & 1.9 \\
\hline 148644 & $\mathrm{C} 3 \mathrm{H} 2 \mathrm{~F} 6 \mathrm{O}$ & 294 & & 2.2 \\
\hline 11665471 & $\mathrm{C} 3 \mathrm{H} 2 \mathrm{~F} 6 \mathrm{O}$ & 286 & & 2.1 \\
\hline 19390374 & $\mathrm{C} 3 \mathrm{H} 2 \mathrm{~F} 7 \mathrm{~N}$ & 295 & & 2.2 \\
\hline 144608 & $\mathrm{C} 3 \mathrm{H} 2 \mathrm{~F} 7 \mathrm{~N}$ & 290 & & 2.0 \\
\hline 15032138 & $\mathrm{C} 3 \mathrm{H} 3 \mathrm{BrF} 4$ & 300 & & 1.9 \\
\hline 2782294 & $\mathrm{C} 3 \mathrm{H} 3 \mathrm{ClF} 4$ & 296 & & 1.8 \\
\hline 14066890 & $\mathrm{C} 3 \mathrm{H} 3 \mathrm{ClF} 4$ & 292 & & 1.7 \\
\hline 22465807 & C3H3F5O & 294 & & 1.5 \\
\hline 9872 & $\mathrm{C} 3 \mathrm{H} 3 \mathrm{~F} 5 \mathrm{O}$ & 297 & 354 [30] & 1.5 \\
\hline 23510551 & C3H3F5O & 295 & & 1.6 \\
\hline 19006646 & C3H3F5O & 282 & & 2.0 \\
\hline 21645339 & C3H3F5O & 289 & & 1.5 \\
\hline 21732907 & $\mathrm{C} 3 \mathrm{H} 3 \mathrm{~F} 6 \mathrm{~N}$ & 299 & & 1.6 \\
\hline 144609 & $\mathrm{C} 3 \mathrm{H} 3 \mathrm{~F} 6 \mathrm{~N}$ & 259 & & 1.1 \\
\hline 12927175 & $\mathrm{C} 3 \mathrm{H} 4 \mathrm{ClF} 3$ & 280 & & 1.2 \\
\hline 18786703 & $\mathrm{C} 3 \mathrm{H} 4 \mathrm{ClF} 3$ & 279 & & 1.1 \\
\hline 2776724 & $\mathrm{C} 3 \mathrm{H} 4 \mathrm{~F} 4$ & 247 & $302-303[30]$ & 1.2 \\
\hline 17763161 & $\mathrm{C} 3 \mathrm{H} 4 \mathrm{~F} 4 \mathrm{O}$ & 293 & & 1.6 \\
\hline 20225807 & C3HClF6O & 309 & & 2.3 \\
\hline 2759273 & C3HF7O & 285 & & 2.2 \\
\hline 144610 & C3HF8N & 279 & & 2.2 \\
\hline 12653369 & C4F4N2 & 301 & & 1.7 \\
\hline 11275686 & $\mathrm{C} 4 \mathrm{H} 2 \mathrm{~F} 8$ & 282 & & 2.7 \\
\hline 15162467 & $\mathrm{C} 4 \mathrm{H} 2 \mathrm{~F} 8 \mathrm{O}$ & 301 & & 2.4 \\
\hline 21243755 & $\mathrm{C} 4 \mathrm{H} 2 \mathrm{~F} 8 \mathrm{O}$ & 312 & & 2.7 \\
\hline 4407544 & $\mathrm{C} 4 \mathrm{H} 2 \mathrm{~F} 8 \mathrm{O}$ & 307 & & 2.7 \\
\hline 18457462 & $\mathrm{C} 4 \mathrm{H} 2 \mathrm{~F} 8 \mathrm{O}$ & 315 & & 3.1 \\
\hline 2736596 & C4H3ClF6 & 307 & $321-322[30]$ & 2.6 \\
\hline 12025746 & $\mathrm{C} 4 \mathrm{H} 3 \mathrm{~F} 7$ & 292 & & 2.4 \\
\hline 15044627 & $\mathrm{C} 4 \mathrm{H} 3 \mathrm{~F} 7$ & 274 & & 2.3 \\
\hline 23236258 & $\mathrm{C} 4 \mathrm{H} 3 \mathrm{~F} 7$ & 289 & & 2.2 \\
\hline 21731035 & $\mathrm{C} 4 \mathrm{H} 3 \mathrm{~F} 7$ & 287 & & 2.1 \\
\hline 22178537 & C4H3F7O & 304 & & 2.3 \\
\hline 5206 & C4H3F7O & 306 & $331[30]$ & 2.3 \\
\hline 19788901 & $\mathrm{C} 4 \mathrm{H} 3 \mathrm{~F} 7 \mathrm{O}$ & 299 & & 1.9 \\
\hline 12554037 & C4H3F7O & 302 & & 2.4 \\
\hline 53436611 & C4H3F7O & 303 & & 2.1 \\
\hline 22102014 & C4H3F7O & 311 & & 2.3 \\
\hline 19037094 & $\mathrm{C} 4 \mathrm{H} 3 \mathrm{~F} 7 \mathrm{O}$ & 318 & & 2.8 \\
\hline 21459300 & C4H4ClF5 & 318 & & 2.6 \\
\hline 21459281 & C4H4ClF5 & 297 & & 1.8 \\
\hline 2778258 & C4H4F6 & 288 & 294 [30] & 2.4 \\
\hline 15576965 & $\mathrm{C} 4 \mathrm{H} 4 \mathrm{~F} 6$ & 288 & & 1.7 \\
\hline 67890 & C4H4F6 & 293 & 298 [30] & 2.5 \\
\hline 10899043 & C4H4F6 & 275 & & 1.6 \\
\hline 15044576 & C4H4F6 & 295 & & 2.1 \\
\hline
\end{tabular}

\begin{tabular}{c|c|c|c|c}
\hline CID & formula & $T_{\mathrm{B}}$ & $T_{\mathrm{B}}$ (lit.) & $E_{\mathrm{r}}$ \\
\hline 21922262 & C4H4F6 & 296 & & 2.1 \\
\hline 21731031 & C4H4F6 & 271 & & 1.5 \\
\hline 20715328 & C4H4F6O & 286 & & 1.9 \\
\hline 19788851 & C4H4F6O & 292 & & 1.5 \\
\hline 21136753 & C4H5F5 & 300 & & 1.8 \\
\hline 21922298 & C4H5F5 & 299 & & 1.8 \\
\hline 11094775 & C4H5F5 & 295 & & 1.8 \\
\hline 15044628 & C4H5F5 & 294 & & 1.8 \\
\hline 21731027 & C4H5F5 & 297 & & 1.6 \\
\hline 21731805 & C4H5F5 & 290 & & 1.5 \\
\hline 15914919 & C4H6F4 & 291 & $315[30]$ & 1.5 \\
\hline 15044629 & C4H6F4 & 288 & & 1.4 \\
\hline 15162466 & C4HClF80 & 314 & & 3.1 \\
\hline 16924 & C4HF90 & 292 & $317-318[30]$ & 2.8 \\
\hline 14620145 & C4HF90 & 303 & & 3.1 \\
\hline 17789749 & CH2F2O & 203 & & 0.6 \\
\hline 22314940 & CHBrF2O & 281 & & 1.2 \\
\hline 18532994 & CHCIF2O & 251 & & 1.2 \\
\hline 73894 & CHF30 & 201 & & 1.0 \\
\hline & & & &
\end{tabular}

Table 5. Compounds in the Pareto-area with $100<\mathrm{GWP}<200$.

\begin{tabular}{c|c|c|c|c}
\hline CID & formula & $T_{\mathrm{B}}$ & $T_{\mathrm{B}}$ (lit.) & $E_{\mathrm{r}}$ \\
\hline 15939370 & C3H3F5 & 265 & & 1.5 \\
\hline 164598 & C3H3F5 & 265 & $296[30]$ & 1.5 \\
\hline 2774090 & C3H3F5O & 290 & $299[30]$ & 1.5 \\
\hline 22164456 & C4H2F8 & 280 & & 2.4 \\
\hline 11042687 & C4H2ClF7O & 318 & & 2.7 \\
\hline 18335861 & C4H3F7O & 290 & & 2.5 \\
\hline 20606324 & C3HCl2F5O & 314 & & 2.5 \\
\hline 21922285 & C4H3F7 & 289 & & 2.1 \\
\hline 56612536 & C4H4F6O & 318 & & 2.4 \\
\hline 19063460 & C4H3F7O & 296 & & 2.3 \\
\hline 15044575 & C4H3F7 & 280 & & 2.2 \\
\hline 21922280 & C4H4F6 & 265 & & 1.7 \\
\hline 10154032 & C3H4F4 & 246 & & 0.95 \\
\hline 14709481 & C4H4F6 & 294 & & 1.8 \\
\hline 20243757 & C2H4F2O & 247 & & 0.94 \\
\hline 21922265 & C4H4F6 & 284 & & 1.5 \\
\hline 2774025 & C4H2Cl2F6 & 318 & $356-357[30]$ & 2.5 \\
\hline 87912 & C3H3ClF4 & 295 & & 1.6 \\
\hline 3028248 & C2HBr2F3 & 312 & $347-348[32]$ & 2.4 \\
\hline 13597428 & C4H4F6 & 302 & & 2.2 \\
\hline & & & &
\end{tabular}

mixture" (R18). The chlorofluorocarbon 2782294 is "dangerous for the ozone layer" (R59).

\section{DISCUSSION}

The ideal insulation gas would boil at $T_{\mathrm{B}}=0 \mathrm{~K}$. Then the gas pressure, and thus the breakdown voltage, in principle could be increased to infinitely high values, disregarding the mechanical stress on the equipment. Hence, for the usage in high voltage equipment the lower limit on $T_{\mathrm{B}}$, and thus on $T_{\mathrm{c}}$, should be as small as possible. Nevertheless, we expect not to prematurely exclude candidate gases by the boundary $T_{\mathrm{c}}>300$ $\mathrm{K}$, as described in Section 2.1. For comparison, $\mathrm{SF}_{6}$ has a critical temperature of $T_{\mathrm{c}}=318.7 \mathrm{~K}$ [33], which is included by the used boundary. Compounds with $T_{\mathrm{B}}$ around room temperature may condensate at lower temperatures or elevated 
pressures and are thus not suitable as insulation gases in pure form. Instead, they may be used as one component in a gas mixture. By this, the ES of a gas such as nitrogen might be significantly increased already by adding only small percentages of a strongly electron-attaching substance [34].

We note that the GWP is a quantity that is uncoupled from the initial gas release of electrical equipment. It reflects the environmental impact in terms of global warming after the emission of $1 \mathrm{~kg}$ of an insulating gas into the atmosphere, as described in Section 2.1. However, the amount of emitted insulating gas from electrical equipment strongly depends on the molecular mass and the viscosity of the gas species. For example, poor gas handling during maintenance work can lead to the entire release of an insulating gas volume into the atmosphere. In this case the amount of emitted gas is proportional to its molecular mass. Another source of gas Table 6. Safety and Risk phrases for the Pareto efficient compounds that are commercially available [30].

\begin{tabular}{|c|c|c|}
\hline CID & Risk phrases & Safety phrases \\
\hline SF6 & $36 / 37 / 38-44$ & $\begin{array}{c}9-24 / 25-26-36 / 37 / 39- \\
38-45-47 \\
\end{array}$ \\
\hline 5708528 & $36 / 37 / 38$ & $\begin{array}{c}23-24 / 25-36 / 37 / 39-38- \\
45 \\
\end{array}$ \\
\hline 91450 & $36 / 37 / 38-44$ & $\begin{array}{c}9-23-24 / 25-26- \\
36 / 37 / 39-38-45-47\end{array}$ \\
\hline 52991879 & $10-36 / 37 / 38$ & $\begin{array}{c}16-23-24 / 25-26- \\
36 / 37 / 39-45 \\
\end{array}$ \\
\hline 11212 & $23 / 24 / 25-36 / 37 / 38-44$ & $\begin{array}{l}13-20-23-24 / 25-26- \\
36 / 37 / 39-38-45-47\end{array}$ \\
\hline 53395686 & & $36 / 37 / 39-41$ \\
\hline 11053485 & $36 / 37 / 38$ & $23-24 / 25-36 / 37 / 39-45$ \\
\hline 61109 & $26-36 / 37 / 38-44$ & $\begin{array}{c}9-23-24 / 25-26- \\
36 / 37 / 39-38-45-47 \\
\end{array}$ \\
\hline 2775851 & $36 / 37 / 38$ & $26-36$ \\
\hline 5708514 & $36 / 37 / 38-44$ & $\begin{array}{c}9-23-24 / 25-26- \\
36 / 37 / 39-38-45-47 \\
\end{array}$ \\
\hline 2776724 & $10,36 / 37 / 38,67$ & $\begin{array}{c}9,16,23,24 / 25,26 \\
36 / 37 / 39,45,51\end{array}$ \\
\hline 2782294 & $36 / 37 / 38-59$ & $\begin{array}{c}3 / 7-23-24 / 25-26- \\
36 / 37 / 39-45-57-61\end{array}$ \\
\hline 67890 & 44 & $\begin{array}{c}9-23-24 / 25-26- \\
36 / 37 / 39-38-45-47 \\
\end{array}$ \\
\hline 15914919 & 12 & 9,16 \\
\hline 16924 & $21 / 22-23-36 / 37 / 38$ & $\begin{array}{c}23-24 / 25-26-36 / 37 / 39- \\
45 \\
\end{array}$ \\
\hline 2736596 & & $\begin{array}{c}/ 7-23-24 / 25-26- \\
36 / 37 / 39-45 \\
\end{array}$ \\
\hline 13529 & $20 / 22-34$ & $26-36 / 37 / 39-45$ \\
\hline 5206 & $18-36 / 37 / 38$ & $\begin{array}{c}15-16-23-24 / 25-33- \\
36 / 37 / 39-45 \\
\end{array}$ \\
\hline 164598 & 44 & $\begin{array}{c}9-23-24 / 25-26- \\
36 / 37 / 39-38-45-47 \\
\end{array}$ \\
\hline 10154032 & 18 & $9-15-16-33$ \\
\hline 5365501 & $12-18-44$ & $\begin{array}{c}9-16-23-24 / 25-26-33- \\
36 / 37 / 39-38-45-47\end{array}$ \\
\hline 12223 & $10-23 / 24 / 25-36 / 37 / 38$ & $\begin{array}{c}23-24 / 25-26-36 / 37 / 39- \\
45 \\
\end{array}$ \\
\hline
\end{tabular}

emission is durable leakage from gas-insulated equipment. For this scenario the leak rate increases with decreasing viscosity of the gas species. The viscosity in turn depends on the molecular mass and microscopic properties of the gas. Nevertheless, we measured the environmental effect of an insulating gas solely by means of its GWP. The GWP is a well-established quantity widely used in literature. It allows rapid comparison of environmental aspects between different compounds and sources. In addition, we wanted to follow a universal screening procedure, which filters out certain compounds independent from technical issues such as different leakage scenarios.

For all compounds, we clearly observe certain trends for the ES and $T_{\mathrm{B}}$. The values of these quantities strongly vary with the elemental composition and the molecular structure. Certainly, for increasing number of F-atoms in a molecule the ES increases due to the higher rate of electron attachment, as can be seen from Table 2 to Table 5. Furthermore, increasing number of $\mathrm{C}$-atoms in a molecule increases the rate of elastic collisions, and thus the ES. The increased value of $T_{\mathrm{B}}$ for larger molecules is the result of increasing van der Waals interaction. It appears particularly interesting that substances of the same molecular formula but different chemical structures may reveal very different values for ES.

The initial set of 1234 compounds does not contain any perfluoro- or hydrofluoro- carbonyl compounds. This chemical class was investigated in detail in previous work [9]. Most ketones and aldehydes with more than 4 carbon atoms were already filtered out by the constraint that the molecular size is limited to 15 atoms, as described in Section 2.1. We can only speculate here that their GWP might be higher than set by the given constraint.

We want to note that our estimation method for $E_{\mathrm{r}}$ and $T_{\mathrm{B}}$, as well as the estimation methods [6] for the GWP, flammability and toxicity are subject to significant uncertainties, and outliers may exist. In general, we find good agreement between our calculated $T_{\mathrm{B}}$ values and values from literature, as shown in Table 2-5. Furthermore, not all identified substitutes meet the desired toxicity- and flammability- criteria, as shown in Table 6. For example one identified compound is the fluorocarbon alkene perfluoroisobutene (CID $=61109$ ), which is very toxic as mentioned in Section 3. The commercially available compounds in Table 6 which, according to safety data sheets, might fulfill basic requirements for a substitute gas are: 5708528, 91450, 11053485, 2775851, 5708514, 164598 and 13529. The latter is "harmful by inhalation and if swallowed" [30]. For the compound 53395686 no safety data sheet was available.

The compounds of Table 2-5 which are not supplied by chemical vendors, might be seen as a proposal list for $\mathrm{SF}_{6}$ substitutes. In addition to the physical and chemical properties of an alternative insulation gas its commercialization is driven by the price of its synthesis. Certainly, a promising candidate might not be an alternative to $\mathrm{SF}_{6}$, if its production is complicated and cost-intensive or in terms of regulatory basis highly restrictive. Providing methods for synthesis, isolation 
and production of chemical compounds to increase its commercial potential for the industry is subject to the large field of organic synthesis, and it is not within the scope of this work.

\section{CONCLUSION}

Out of a large library of 56000 compounds from the PubChem database a few most promising gaseous dielectrics were identified. We therefore adopted the subset of around 1200 compounds, which the authors derived by virtual screening based on environmental, safety and thermodynamic criteria. For these compounds of low global warming potential, low toxicity and low flammability the electric strength and boiling point were estimated. A quantitative investigation of the electric strength should follow for the topcandidates, e.g. by swarm parameter measurements and the derivation of the critical electric field strength.

\section{REFERENCES}

[1] J.C. Devins, "Replacement Gases for $\mathrm{SF}_{6}$ ", IEEE Trans. Dielectr. Electr. Insul, Vol. 15, pp. 81-86, 1980.

[2] L.G. Christophorou and R.J. Van Brunt " $\mathrm{SF}_{6} / \mathrm{N}_{2}$ mixtures: basic and HV insulation properties", IEEE Trans. Dielectr. Electr. Insul, Vol. 2, pp. 952-1003, 1995.

[3] L.G. Christophorou, J.K. Olthoff, and D.S. Green, "Gases for Electrical Insulation and Arc Interruption: Possible Present and Future Alternatives to Pure SF 6 ", National Inst. Sci, Techn. (NIST), Washington Dc, USA, Technical Note 1425, 1997.

[4] L. Niemeyer, "A Systematic Search for Insulation Gases and Their Environmental Evaluation", Gaseous Dielectrics VIII, pp. 459-464, 1998.

[5] B. K. Shoichet, "Virtual screening of chemical libraries", Nature, Vol. 432, pp. 862-865, 2004

[6] A. Kazakov, M. O. McLinden, and M. Frenkel, "Computational design of new refrigerant fluids based on environmental, safety and thermodynamic characteristics”, Ind. Eng. Chem. Res., Vol. 51, pp. 12537-12548, 2012

[7] E. Bolton, Y. Wang, P. A. Thiessen, and S. H. Bryant, "PubChem: Integrated platform of small molecules and biological activities", Annual Reports in Computational Chemistry, American Chemical Society: Washington, DC, Vol. 4, Chapter 12, 2008

[8] M. Rabie, D. A. Dahl, S. M. A. Donald, M. Reiher, and C. M. Franck, "Predictors for gases of high electric strength", IEEE Trans. Dielectr. Electr. Insul., Vol. 20, No 3, pp. 856-863, 2013.

[9] M. Rabie and C. M. Franck, "Predicting the electric strength of proposed SF6 replacement gases by means of density functional theory", Int'l Sympos. High Voltage Eng. (ISH), Seoul, Korea, pp. 1381-1386, 2013.

[10] ANSI/ASHRAE Standard 34-2010: Designation and Safety Classification of Refrigerants; American Society of Heating, Refrigerating and Air-Conditioning Engineers, Inc.: Atlanta, GA, 2010.

[11] J. T. Houghton, L. G. Meira Filho, B. A. Callander, N. Harris, A. Kattenberg, and K. Maskell (eds.) "Climate Change 1995: The Science of Climate Change", Cambridge University Press: New York, 1996.

[12] J. J. P. Stewart, "Optimization of parameters for semiempirical methods $\mathrm{V}$ : Modification of NDDO approximations and application to 70 elements", J. Mol. Model., Vol. 13, pp. 1173-1213, 2007.

[13] E. S. C. Kwok and R. Atkinson, "Estimation of hydroxyl radical reaction rate constants for gas phase organic compounds using a structure reactivity relationship: An update", Atmos. Environ., Vol. 29, pp 1685-1695, 1995.

[14] M. J. Frisch, G. W. Trucks, H. B. Schlegel, G. E. Scuseria, M. A. Robb, J. R. Cheeseman, G. Scalmani, V. Barone, B. Mennucci, G. A Petersson, H. Nakatsuji, M. Caricato, X. Li, H. P. Hratchian, A. F. Izmaylov, J. Bloino, G. Zheng, J. L. Sonnenberg, M. Hada, M. Ehara, K. Toyota, R. Fukuda, J. Hasegawa, M. Ishida, T. Nakajima, Y. Honda, O.

Kitao, H. Nakai, T. Vreven, J. A. Montgomery, Jr., J. E. Peralta, F. Ogliaro, M. Bearpark, J. J. Heyd, E. Brothers, K. N. Kudin, V. N. Staroverov, T. Keith, R. Kobayashi, J. Normand, K. Raghavachari, A. Rendell, J. C. Burant, S. S. Iyengar, J. Tomasi, M. Cossi, N. Rega, J. M. Millam, M. Klene, J. E. Knox, J. B. Cross, V. Bakken, C. Adamo, J. Jaramillo, R. Gomperts, R. E. Stratmann, O. Yazyev, A. J. Austin, R. Cammi, C. Pomelli, J. W. Ochterski, R. L. Martin, K. Morokuma, V. G. Zakrzewski, G. A. Voth, P. Salvador, J. J. Dannenberg, S. Dapprich, A. D. Daniels, O. Farkas, J. B. Foresman, J. V. Ortiz, J. Cioslowski, and D. J. Fox, Gaussian 09, Revision B.01; Gaussian, Inc.: Wallingford, CT, 2010.

[15] A. L. Mascarelli, "A bright future for the Montreal Protocol”, Environ. Sci. Technol., Vol. 44, pp. 1518-1520, 2010.

[16] R.E. Robson, P. Nicoletopoulos, B. Li, and R.D. White, "Kinetic theoretical and fluid modelling of plasmas and swarms: the big picture", Plasma Sources Science and Technology, Vol. 17, pp. 024020, 2008.

[17] N. L. Aleksandrov, "Three-body electron attachment to a molecule", Usp. Fiz. Nauk., Vol 154, pp. 177-206, 1988.

[18] S. Pancheshnyi, "Effective ionization rate in nitrogen-oxygen mixtures", J. Phys. D: Appl. Phys., Vol. 46, pp. 155201, 2013.

[19] W. A. Wilson, J.H. Simons, and T.J. Brice, "The Dielectric Strength of Gaseous Fluorocarbons”, J. Appl. Phys., Vol. 21, pp. 203-205, 1950.

[20] R. W. Crowe and J. C. Devins, "Sparking Potential and Molecular Structure of Unsaturated Hydrocarbon Gases", J. Chem. Phys., Vol. 33, pp. 413-18, 1960 .

[21] A. E. D. Heylen and T.J. Lewis "The electrical strength of hydrocarbon gases”, British. J. Appl. Phys., Vol. 7, pp. 411-415, 1956.

[22] K. P. Brand, "Dielectric strength, boiling point and toxicity of gases different aspects of the same basic molecular properties", IEEE Trans. Dielectr. Electr. Insul, Vol. 17, pp. 451-456, 1982.

[23] N. Meurice, E. Sandre, A. Aslanides, and D.P. Vercauteren, "Simple theoretical estimation of the dielectric strength of gases", IEEE Trans. Dielectr. Electr. Insul, Vol. 11, pp. 946-948, 2004.

[24] R. Ahlrichs, M. Bär, M. Häser, H. Horn, and C. Kölmel, "Electronic structure calculations on workstation computers: The program system turbomole", Chemical Phys. Lett., Vol. 162, pp. 165-169, 1989.

[25] A.D. Becke, "Density-functional exchange-energy approximation with correct asymptotic behavior", Phys. Rev. A, Vol. 38, pp. 3098-3100, 1988.

[26] J.P. Perdew, "Density-functional approximation for the correlation energy of the inhomogeneous electron gas", Phys. Rev. B, Vol. 33, pp. $8822-8824,1986$.

[27] A. Schaefer, C. Huber, and R. Ahlrichs, "Fully optimized contracted Gaussian basis sets of triple zeta valence quality for atoms Li to Kr", J. Chem. Phys., Vol. 100, pp. 5829-5835, 1994

[28] F. Weigend, F. Furche, and R. Ahlrichs, "Gaussian basis sets of quadruple zeta valence quality for atoms H-Kr", J. Chem. Phys., Vol. 119 , pp. 12753-12762, 2003.

[29] F. Paschen, " Ueber die zum Funkenübergang in Luft, Wasserstoff und Kohlensäure bei verschiedenen Drucken erforderliche Potentialdifferenz", Annalen der Physik, Vol. 273, pp. 69-96, 1889.

[30] SynQuest Laboratories, http://www.synquestlabs.com/, 2013.

[31] Royal Society of Chemistry, http://www.chemspider.com/, 2014.

[32] Matrixscientific, http://www.matrixscientific.com/, 2013.

[33] Air Liquide Gas Encyclopedia. Retrieved 02 June 2013.

[34] C. M. Franck, D. A. Dahl, M. Rabie, P. Haefliger, and M. Koch, "An Efficient Procedure to Identify and Quantify New Molecules for Insulating Gas Mixtures “, Contrib. Plasma Phys., Vol. 54, pp. 3 - 13, 2014.

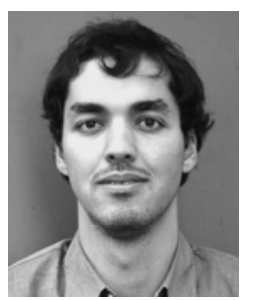

(M'04-SM'11) from the University
Mohamed Rabie was born in Innsbruck, Austria in 1985. He received a diploma in physics from the University of Innsbruck in 2011. There he was working on one-dimensional quantumgases. Currently he is doing his Ph.D. degree at the Institute for Power Systems and High Voltage Technology, ETH Zurich, Switzerland.

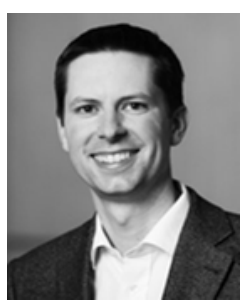

Christian M. Franck received a diploma in physics of Kiel, Germany in 1999 
and the Ph.D. degree in physics from the University of Greifswald, Germany in 2003. He was with the Swiss corporate research center of ABB during 2003-2009 as a Scientist and Group Leader for gas circuit breakers and high voltage systems. Currently, he is an Assistant Professor for High Voltage Technology at the Swiss Federal Institute of Technology (ETH), Zurich, Switzerland. 